\title{
Evaluation of the portio vaginalis of the cervix by B-mode and colour Doppler ultrasound in Simmental cattle
}

\author{
Ali Risvanli ${ }^{1}$, Tarik Safak ${ }^{2}$, Oznur Yilmaz ${ }^{3}$, Burak Yuksel ${ }^{2}$, \\ Mehmet Akif Kilinc ${ }^{4}$, Ibrahim Seker ${ }^{5}$
}

\begin{abstract}
${ }^{1}$ Kyrgyz-Turkish Manas University, Faculty of Veterinary Medicine, Department of Obstetrics and Gynecology, Bishkek, Kyrgyzstan

${ }^{2}$ University of Firat, Faculty of Veterinary Medicine, Department of Obstetrics and Gynecology, Elazig, Turkey ${ }^{3}$ University of Siirt, Faculty of Veterinary Medicine, Department of Obstetrics and Gynecology, Siirt, Turkey ${ }^{4}$ University of Bingol, Faculty of Veterinary Medicine, Department of Obstetrics and Gynecology, Bingol, Turkey

${ }^{5}$ University of Firat, Faculty of Veterinary Medicine, Department of Zootechny, Elazig, Turkey
\end{abstract}

Received May 31, 2021

Accepted December 16, 2021

\begin{abstract}
This study was aimed to reveal the relationship between the B-mode and colour Doppler ultrasonography features of the portio vaginalis of the cervix in Simmental cattle with different physiological and pathological conditions of genital organs. For this purpose, 90 cattle were used in the study. The length, width and circumference of the portio vaginalis of the cervix were measured ultrasonographically using a $5 \mathrm{MHz}$ linear probe. In addition, the portio vaginalis of the cervix was ultrasonographically evaluated in terms of echogenicity, cystic formations, calcification and integrity of its borders. Regarding the colour Doppler ultrasonography, measurements of the vascular distribution category, vascular density and the vascular morphological appearance were made. In this study, it was found that the rate of irregularity of the border of the portio vaginalis in B-mode ultrasonography according to the pregnancy status was $10.9 \%$ in non-pregnant cows, while this was not observed in pregnant cows $(0.0 \%)$. According to the metritis status, it was observed that the rate of regularity of the border of the portio vaginalis was higher in animals with metritis $(45.5 \%)$ in B-mode ultrasonography. As a result, it was concluded that there were significant changes in the B-mode and colour Doppler ultrasonography characteristics of the portio vaginalis of the cervix in different physiological and pathological conditions in cattle, and that hypotheses can be developed regarding the fertility of the animals by evaluating these characteristics.
\end{abstract}

\section{Calcification, echogenicity, cystic formation}

Examination of the reproductive organs in cattle usually begins with finding the cervix uteri. The position of the cervix uteri varies depending on the pregnancy status and the number of pregnancies. It is found in the pelvic cavity in sexually immature animals, but in pregnant animals, it extends towards the cranial part of the pelvis. As the pregnancy progresses, it begins to be pulled cranially and ventrally by the pregnant uterus. The cervical canal consists of mucosal folds that almost completely close the canal. In cattle, the largest caudal part of the cervix (portio vaginalis) projects into the lumen of the vagina and the fornix is surrounded by the vagina. Cervix uteri has a harder consistency and a cylindrical structure compared to the uterus. It is approximately $2 \mathrm{~cm}$ in diameter and $4 \mathrm{~cm}$ in length in heifer. In cows, it is $4-5 \mathrm{~cm}$ in diameter and $8 \mathrm{~cm}$ in length depending on the number of births (Gürler and Findik 2019; Keskin and Macun 2019).

The cervix uteri is detected at the level of the urinary bladder by ultrasonography in non-pregnant cows. The cervix uteri can be identified by the hyperechoic view of the cervical canal and detection of the cervical rings. The midline of the corpus uteri and the cornu uteri are displayed just anterior to the cervix uteri (Kähn 2004; Keskin and Macun 2019).

Address for correspondence:

Mehmet Akif Kilinc

Department of Obstetrics and Gynecology

Faculty of Veterinary Medicine

University of Bingol, Bingol, Turkey
E-mail: makilinc@bingol.edu.tr

Tel: + $904242370000 / 6169$

Fax: + 904242388173

http://actavet.vfu.cz/ 
Cervix uteri measurement by ultrasonography is used to evaluate the reproductive status in cows (LeBlanc et al. 2002). In addition, ultrasonography is used in females to follow cervical dilatation at the time of delivery through abdominal, vaginal, and transperineal routes. In order to follow the cervical dilatation, the length of the cervix, the width of the internal cervical os and the dilatation of the cervical canal are followed up by ultrasonography in females. It has also been shown that it is possible to continuously measure the cervical opening in cows from the first stage of birth to the hatching stage of the offspring using ultrasound cervimetry (Breeveld-Dwarkasing et al. 2002).

Five different techniques are used in Doppler ultrasonography: 1) continuous-wave Doppler; 2) pulsed-wave Doppler; 3) colour Doppler; 4) power Doppler; 5) spectral Doppler or Duplex scanning. The most commonly used form of Doppler ultrasonography in radiological applications is colour Doppler ultrasonography. Colour Doppler ultrasonography provides qualitative information about blood flow and vascularization in tissues. Accordingly, using the colour Doppler technique, information on the vascular distribution category, vascular density, and vascular morphological appearance of the target organ and tissue and their pathological changes can be obtained (Moorthy 2002; Mrdjen 2013).

This study was aimed to reveal the relationship between the B-mode and colour Doppler ultrasonography features of the portio vaginalis of the cervix in Simmental cattle with different physiological and pathological conditions of genital organs and thus determine whether or not the ultrasonographic features of the portio vaginalis can be used to evaluate the reproductive status in cattle.

\section{Materials and Methods}

Animals

The animals were selected from among 1,000 animals brought to the Frrat University Animal Hospital. Ninety clinically healthy Simmental cattle aged 2-8 years and weighing 450-500 kg were included in the study. The body condition scores of the animals varied between 3-3.5.

Information regarding the age, lactation period, lactation frequency, pregnancy status, gestation period and milk yield of the animals to be examined was obtained. The ovaries and the uteri of the animals were examined with transrectal ultrasonography and the number and size of the follicles, the number and size of the corpus luteum and the presence of metritis were determined.

The animals were immobilized as much as possible during the ultrasonographic examination. The animals were adapted to the environment by waiting for $10 \mathrm{~min}$. Doppler ultrasound was suspended in cases where the animal was moving or in which the respiratory rate increased during the examination procedures (Erdogan et al. 2016).

The anatomical position of the portio vaginalis of the cervix was determined by rectal examination after the animal's faecal material was evacuated. Analyses were performed by activating the B-Mode with a $5 \mathrm{MHz}$ linear probe and colour Doppler mode command (Mindray DC-T6 Color Doppler Ultrasound System, Shenzhen, China). After having determined the anatomical position of the portio vaginalis of the cervix, the insonation angle for the colour Doppler was adjusted to $60^{\circ}$. The linear probe was held vertically in a light contact with the portio vaginalis of the cervix.

\section{B-mode ultrasonography measurement}

The length (dorsoventral length, $\mathrm{cm}$ ), width (caudocranial length, $\mathrm{cm}$ ) and circumference (cm) of the portio vaginalis of the cervix were measured using a $5 \mathrm{MHz}$ linear probe. In addition, the portio vaginalis of the cervix was evaluated in terms of echogenicity (as hyper-, hypo- and anechogenic), cystic formations, calcification and border integrity (Plate I, Fig. 1).

\section{Colour Doppler ultrasonography measurement}

This was performed as described by Risvanli et al. (2019). Measurements were made accordingly regarding the vascular distribution category, vascular density and the vascular morphological appearance in the portio vaginalis of the cervix. Under the title of vascular distribution category, the vascularization was evaluated as avascular, capsular, mixed, central, mozaic and peripheral, according to its localization in the portio vaginalis of the cervix. According to the vascular density, the grouping was made as type 1, type 2, type 3 and type 4 , from low to high amount of vascularization. In relation to the vascular morphological appearance, vascularization in the portio vaginalis of the cervix was grouped as linear, distortion, branching and uncertain (Plate I, Fig. 2 and Plate II, Fig. 3). 
Statistical analysis

First, the descriptive statistics of the data obtained for some dimensions (width, length and circumference) of the portio vaginalis of the cervix examined in the study were calculated. Then, it was evaluated whether the data provided normality analysis and parametric test assumptions. Some measurements of the portio vaginalis of the cervix according to various factors (such as age, lactation frequency, lactation period, corpus luteum diameter, gestational status and metritis status) were analysed between the groups. One-way analysis of variance and independent Student's $t$-test in which the means of two independent groups were compared, were used. Chi-square test and Fisher's Exact Test were used in the comparisons of different factors for the categorical data of the parameters examined (echogenicity of the portio vaginalis of the cervix, calcification status, appearance of its borders, vascular morphological appearance, vascular density and vascular distribution category) (Akgül 1997). Spearman test was used to determine the correlations between the categorical parameters and Pearson correlation test was used to determine the correlations between the other parameters. All calculations and tests were carried out with the SPSS 22.0 version program (Anonymous 2016).

\section{Results}

As a result of the analyses performed, no difference was found between the ultrasonographic width, length and circumference measurements of the portio vaginalis according to the age of the animals, lactation period, number of lactations, presence of corpus luteum, pregnancy and metritis $(P>0.05)$.

When the echogenicity, calcification and border appearance of the portio vaginalis were examined according to age groups, no difference between the groups was observed $(P>0.05)$. No significant difference was found in the vascular morphological appearance, vascular density and vascular distribution category of the portio vaginalis according to age groups $(P>0.05)$.

When the vascular distribution category measurements in the colour Doppler of the portio vaginalis were evaluated according to lactation frequency, it was found that avascularity was higher in all lactation frequency categories. Vascular density was the highest in the central in the first $(33.3 \%), 4^{\text {th }}$ and above $(42.9 \%)$ lactation animals, and the lowest in the peripheral in second-third $(0.0 \%)$ lactation animals $(P=0.03)$.

When the distribution of the results was examined according to the number of lactations, echogenicity, calcification, border appearance, vascular morphological appearance and vascular density of the portio vaginalis, no difference between the groups was found $(P>0.05)$.

When the distribution of the results was examined for the echogenicity, calcification, border appearance of the portio vaginalis, vascular morphological appearance, vascular distribution category and vascular density according to the lactation period, no difference between the groups was found $(P>0.05)$.

When the distribution of the results was examined for the echogenicity, calcification, border appearance of the portio vaginalis, vascular morphological appearance, vascular distribution category and vascular density according to the presence of corpus luteum, no difference between the groups was found $(P>0.05)$.

Irregularity of the border of the portio vaginalis was found in non-pregnant cattle $(10.9 \%)$, but this was not found in pregnant cattle $(P=0.03)$. When the distribution of the results was examined for the echogenicity, calcification, vascular morphological appearance, vascular distribution category and vascular density of the portio vaginalis according to the pregnancy status, no difference between the groups was found $(P>0.05)$.

According to the metritis status, the rate of irregularity of the border of the portio vaginalis in B-mode ultrasonography was found to be higher in animals with metritis $(45.5 \%)(P=0.03)$ (Table 1). When the distribution of the results was examined for the echogenicity, calcification, vascular morphological appearance, vascular distribution category and vascular density of the portio vaginalis according to the metritis status, no difference between the groups was found $(P>0.05)$. 
Table 1. Evaluation of the border appearance of the portio vaginalis in B-mode ultrasonography according to the metritis status.

\begin{tabular}{cccccr}
\hline & & & Appearance of the border & \\
\multicolumn{2}{c}{ Factors } & & Regular & Irregular & Total \\
\hline Metritis & Positive & $\mathrm{n}$ & 6 & 5 & 11 \\
& & $\%$ & 54.5 & 45.5 & 100 \\
& Negative & $\mathrm{n}$ & 77 & 2 & 79 \\
& & $\%$ & 97.5 & 2.5 & 100 \\
& & & 0.000 & \\
\hline
\end{tabular}

When the correlation coefficients $(r)$ and the significance levels between some measurements of the portio vaginalis (width, length, and circumference) and its echogenicity, calcification status, appearance of the borders, vascular morphological appearance, vascular density and vascular distribution category were examined, a negative correlation was determined between the width of the portio vaginalis $(r=-0.29)$ and its circumference $(r=-0.27)$, and its echogenicity $(P<0.05)$. Again, a positive correlation between the width $(r=0.44)$ and the circumference $(r=0.72)$ of the portio vaginalis was observed $(P<0.05)$. In addition, there was a positive correlation between the length of the portio vaginalis and vascular morphological appearance $(r=0.24)(P<0.01)$, and vascular density $(r=0.28)(P<0.05)$ (Table 2$)$.

When the calcification and echogenicity $(r=0.84)$ of the portio vaginalis were examined, a positive correlation was observed $(P<0.05)$. A negative correlation was found between the vascular morphological appearance and echogenicity $(r=-0.27)$ of the portio vaginalis $(P<0.01)$. A positive correlation was observed between the vascular morphological appearance of the portio vaginalis and the border appearance $(r=0.24)$ and the vascular distribution category $(r=0.87)(P<0.05)$. A positive correlation was observed between the vascular density of the portio vaginalis and vascular morphological appearance $(r=0.94)$ and the vascular distribution category $(r=0.83)(P<0.05)$ (Table 3$)$.

Table 3. Correlation coefficients $(r)$ and significance levels between the examined features of the portio vaginalis of the cervix.

\begin{tabular}{llllll}
\hline $\begin{array}{l}\text { Features }(\mathrm{n}=90) \\
\text { Echogenicity }\end{array}$ & Echogenicity & Calcification & Border & VDC & VMA \\
\hline Calcification & $0.84(P<0.05)$ & & & & \\
Border & -0.17 & -0.09 & & & \\
VDC & -0.18 & -0.11 & 0.14 & & \\
VAM & $-0.27(P<0.01)$ & -0.12 & $0.24(P<0.01)$ & $0.87(P<0.05)$ & \\
VD & $-0.26(P<0.01)$ & -0.15 & 0.20 & $0.83(P<0.05)$ & $0.94(P<0.05)$ \\
\hline
\end{tabular}

VDC - vascular distribution category; VMA - vascular morphological appearance; VD - vascular density

\section{Discussion}

In the literature reviews we conducted within the scope of this research subject, we could not find a study evaluating either the cervix uterus or the portio vaginalis by colour Doppler ultrasonography in cattle. Previous studies have only measured the diameter and length of the cervix uteri in B-mode ultrasonography. Numerous studies have been conducted in the past to investigate the relationship between the cervix and the uterus size in cows. 
It has been reported that cows with clinical endometritis $(4.2 \mathrm{~cm})$ have a larger cervical diameter than those without clinical endometritis (Brick et al. 2012). LeBlanc et al. (2002) reported that the cervical diameter was a better determinant criterion in the evaluation of the status of the reproductive organs of cows, compared to the diameter of the uterus, and that the best time to make this assessment was the $3^{\text {rd }}$ week postpartum. However, it has been suggested that the effectiveness of the measurement of the cervical diameter may increase when combined with techniques such as intrauterine fluid monitoring. In healthy cows, the cervix diameter is suggested to be $<5 \mathrm{~cm}$ by the $40^{\text {th }}$ day postpartum (Kasimanickam et al. 2004; Sheldon et al. 2006). Poock et al. (2020) reported that the fertility indicators were lower in Jersey cattle with a large cervix diameter. In a study conducted to investigate the effect of PGF $2 \alpha$ injection on cervix involution in the $25-30^{\text {th }}$ days postpartum in primiparous cows with no postpartum problems (Salar et al. 2013), the mean diameter of the cervix before the first PGF2 $\alpha$ injection was $37.74 \pm 1.58 \mathrm{~mm}$, then decreased to $26.34 \pm 1.48 \mathrm{~mm}$ before the second PGF2 $\alpha$ injection, and $26.21 \pm 0.92 \mathrm{~mm} 5$ days later, in the control group, these values were $41.42 \pm 0.66$, $28.66 \pm 1.07$ and $28.52 \pm 0.93 \mathrm{~mm}$, respectively. In this study, it was found that the rate of irregularity of the border of the portio vaginalis in B-mode ultrasonography was higher in animals with metritis $(45.5 \%)$. When the distribution of the results was examined for the echogenicity, calcification, vascular morphological appearance, vascular distribution category and the vascular density of the portio vaginalis according to the metritis condition, no difference between the groups was found. It was concluded that this may be due to varying degrees of inflammation of the portio vaginalis in animals with metritis.

Poock et al. (2020) found that cows with a cervical diameter of $\geq 2.54 \mathrm{~cm}$ were $0.44 \times$ more likely to have a corpus luteum on ultrasound examination than cows with a cervix diameter of $<2.54 \mathrm{~cm}$. In the presented study, when the distribution of results of the width, length, circumference, echogenicity, calcification, border appearance of the portio vaginalis, vascular morphological appearance, vascular distribution category and the vascular density was examined according to the presence of corpus luteum, it was seen that there was no difference between the groups.

The Doppler ultrasonography technique in cows is used to evaluate the physiological and pathological conditions of various organs and tissues of animals. However, pulsed-wave Doppler ultrasonography is mostly preferred (Starke et al. 2011; Brozos et al. 2012; Dzięcioł et al. 2014). Pulsedwave Doppler ultrasonography does not provide sufficient information on blood supply in small structures such as the lymph node, ovary, corpus luteum and tumours. At this point, colour Doppler ultrasonography emerges as a useful application for analysing the vascularization of such tissues. Unfortunately, 
analysis of the results obtained with this technique is difficult. Since it is subjective and repeatable, it cannot be used to evaluate the numerical data (Dzięcioł et al. 2014). In the present study, in the evaluation of the portio vaginalis by colour Doppler ultrasonography, a positive correlation was found between the length of the portio vaginalis and the vascular morphological appearance and vascular density, between the vascular density, vascular morphological appearance and vascular distribution category, and between the vascular morphological appearance and border appearance and the vascular distribution category. A negative correlation was found between the vascular morphological appearance and the echogenicity of the portio vaginalis.

It was concluded that apart from the evaluation of the portio vaginalis by B-mode ultrasonography, the use of indicators such as vascular distribution category, vascular morphological appearance and vascular density, which are examined with colour Doppler ultrasonography, would be beneficial in the ultrasonographic evaluation of the genital organs of cows. In addition, a need was observed for new studies to correlate the colour Doppler ultrasonography measurements of the portio vaginalis with the fertility indicators of the animal.

\section{References}

Akgül A 1997: Statistical analysis techniques in medical researches (in Turkish). Ankara, Turkey: YOK Press. Anonim 2016: SPSS 22.0 statistical package in social sciences for windows. Chicago, USA.

Breeveld-Dwarkasing VNA, Struijk PC, Eijskoot F, Lotgering FK, van Dissel-Emiliani FMF, Van der Weyden GC, Taverne MAM 2002: Ultrasonic cervimetry to study the dilatation of the caudal cervix of the cow at parturition. Theriogenology 57: 1989-2002

Brick T, Schuenemann G, Bas S, Daniels J, Pinto C, Rings D, Rajala-Schultz P 2012: Effect of intrauterine dextrose or antibiotic therapy on reproductive performance of lactating dairy cows diagnosed with clinical endometritis. J Dairy Sci 95: 1894-1905

Brozos CN, Pancarci MS, Valenci J, Beindorff N, Tsousis G, Kiossis E, Bollwein H 2012: Effect of oxytocin infusion on luteal blood flow and progesterone secretion in dairy cattle. J Vet Sci 13: 67-71

Dzięcioł M, Scholbach T, Stańczyk E, Ostrowska J, Kinda W, Woźniak M, Kiełbowicz Z 2014: Dynamic tissue perfusion measurement in the reproductive organs of the female and male dogs. Bull Vet Inst Pulawy 58: 149-155

Erdogan G, Cetin H, Ceylan A, Serin I, Beceriklisoy HB 2016: Comparison of foetal growth in singleton 1 and twin pregnancies by B-mode and Doppler ultrasonography in Karya ewes. Turk J Vet Anim Sci 40: 616-621

Gürler H, Findık M 2019: Morphology of the female reproductive system (in Turkish). In: Semacan A, Kaymaz M, Fındık M, Rişvanlı A, Köker A (Eds): Obstetrics and Gynecology in Farm Animals (in Turkish). Malatya, Turkey: Medipres, pp. 33-38

Kähn W 2004: Veterinary Reproductive Ultrasonography. Schlütersche Verlagsanstalt und Druckerei GmbH und Co, Hannover, Germany, pp. 113-118

Kasimanickam R, Duffield TF, Foster RA, Gartley CJ, Leslie KE, Walton JS, Johnson WH 2004: Endometrial cytology and ultrasonography for the detection of subclinical endometritis in postpartum dairy cows. Theriogenology 62: 9-23

Keskin A, Macun HC 2019: Examination of genital organs (in Turkish). In: Semacan A, Kaymaz M, Findık M, Rişvanlı A, Köker A (Eds): Obstetrics and Gynecology in Farm Animals (in Turkish). Malatya, Turkey: Medipres, pp. 67-91

LeBlanc SJ, Duffield TF, Leslie KE, Bateman KG, Keefe GP, Walton JS, Johnson WH 2002: Defining and diagnosing postpartum clinical endometritis and its impact on reproductive performance in dairy cows. J Dairy Sci 85: 2223-2236

Moorthy RS 2002: Doppler ultrasound. Med J Armed Forces India 58: 1-2

Mrdjen S 2013: Basic principles of Doppler ultrasonography. In European Congress of Radiology. Poster No. C-0363.

Poock SE, Melendez P, Caldeira MO, Moore SG, Mayo LM, Molina-Coto R, Lucy MC 2020: Evaluation of cervical and uterine size, at 4 weeks postpartum, as a predictor of subsequent fertility in Jersey cattle. Reprod Domest Anim 55: 915-921

Risvanli A, Dogan H, Safak T, Kilic MA, Seker I 2019: The relationship between mastitis and the B-mode, colour Doppler ultrasonography measurements of supramammary lymph nodes in cows. J Dairy Res 86: $315-318$

Salar S, Baştan A, Duraloğlu A 2013: The effect of postpartum PGF2 $\alpha$ administration on cervical involution in primiparous cows (in Turkish). Vet Hek Dern Derg 84: 31-35

Sheldon IM, Lewis GS, LeBlanc S, Gilbert RO 2006: Defining postpartum uterine disease in cattle. Theriogenology 65: 1516-1530 
Starke A, Schmidt S, Haudum A, Scholbach T, Wohlsein P, Beyerbach M, Rehage J 2011: Evaluation of portal blood flow using transcutaneous and intraoperative Doppler ultrasonography in dairy cows with fatty liver. J Dairy Sci 94: 2964-2971 
Plate I

Risvanli A. et al.: Evaluation ... pp. 003-009

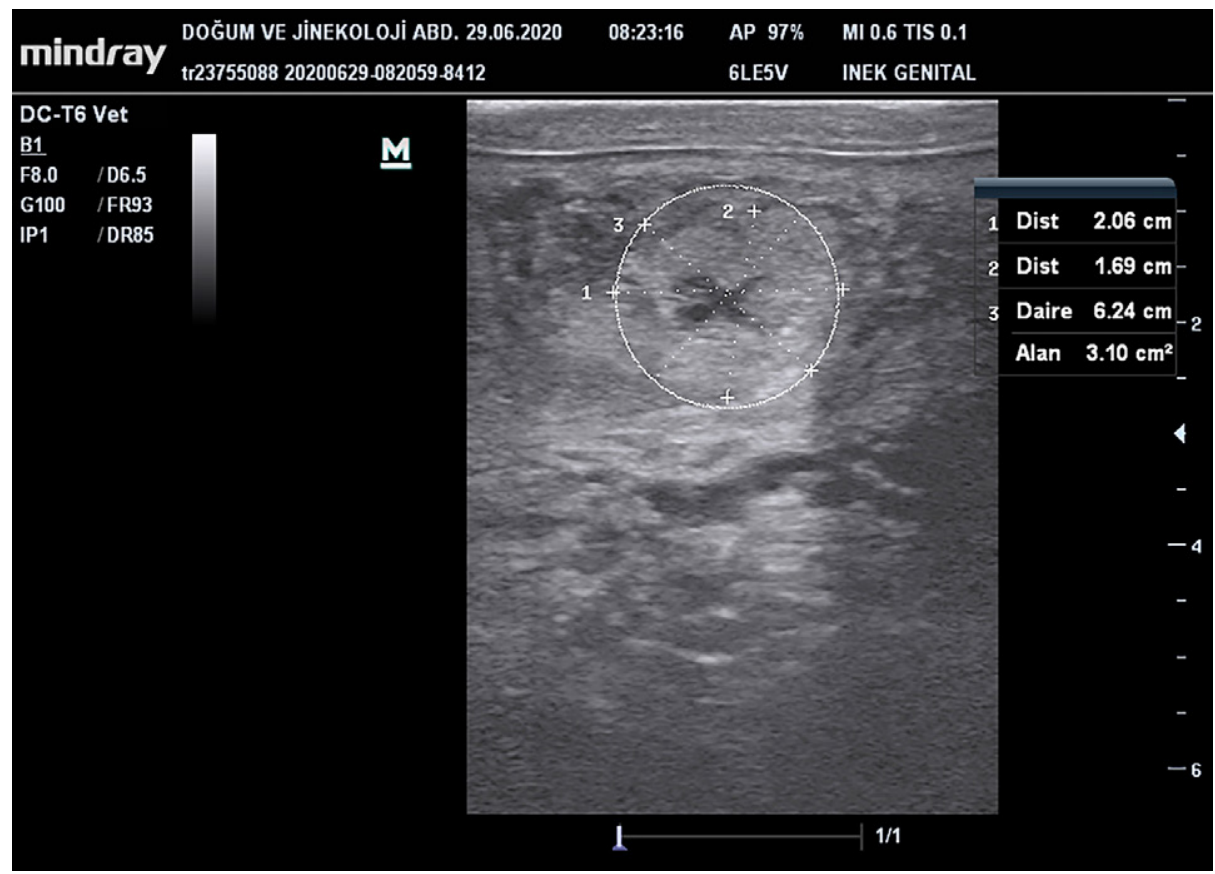

Fig. 1. Measurements of the portio vaginalis made by B-mode ultrasonography

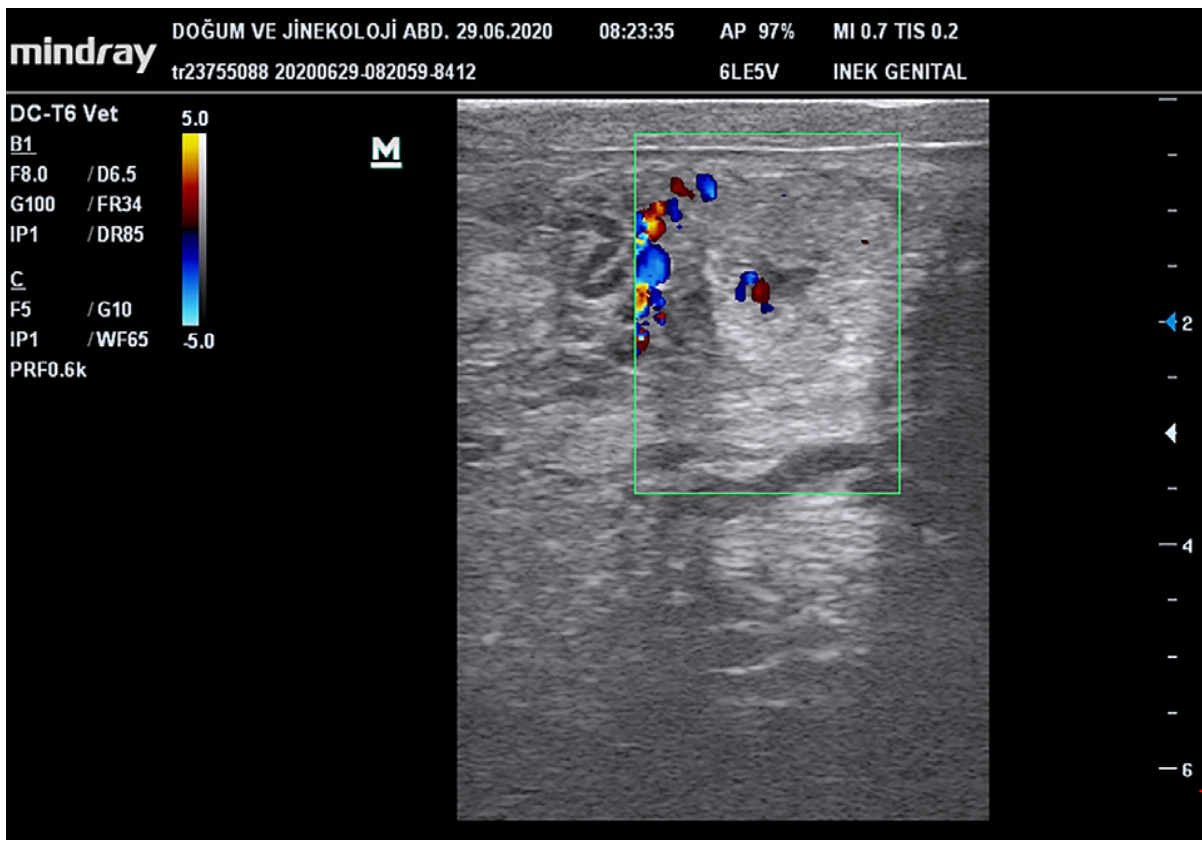

Fig. 2. Colour Doppler ultrasonography measurements of the portio vaginalis. Vascular distribution category: central; vascular morphological appearance: linear; vascular density: type 2 


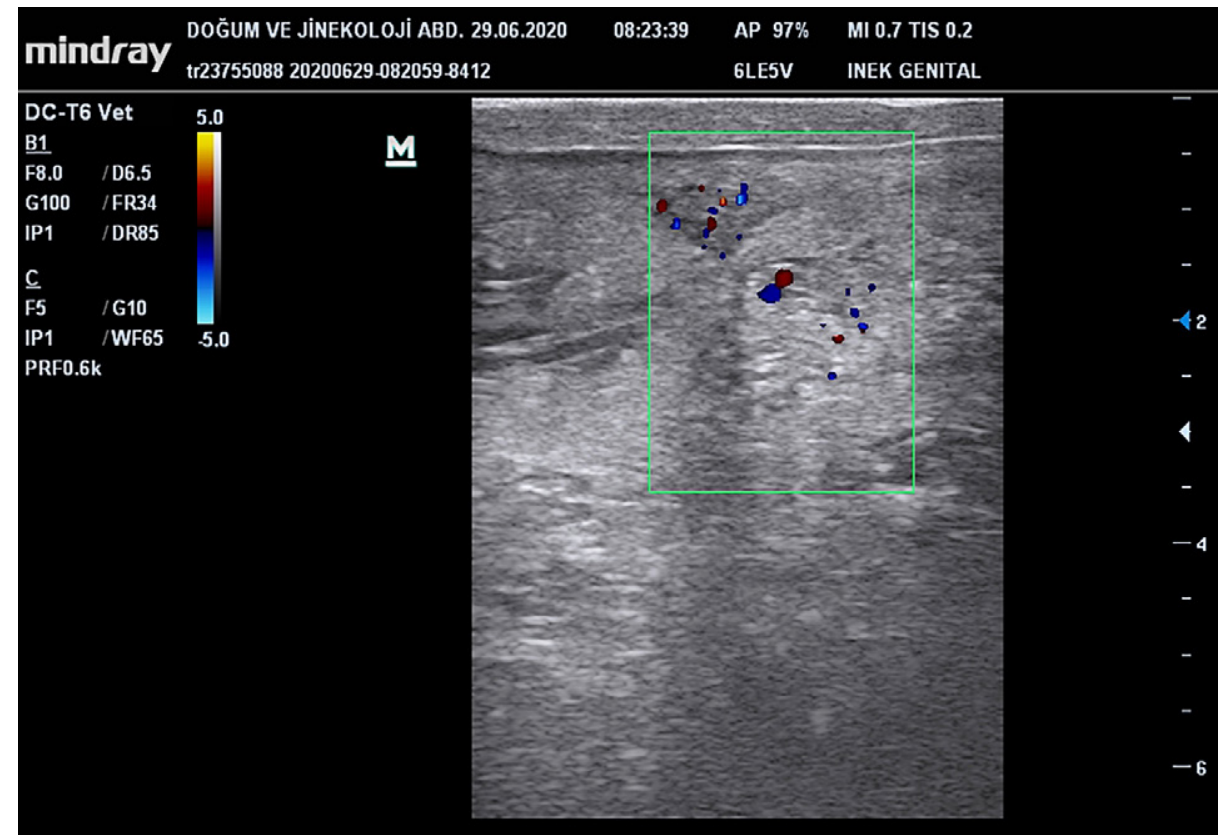

Fig. 3. Colour Doppler ultrasonography measurements of the portio vaginalis. Vascular distribution category: mixed; vascular morphological appearance: uncertain; vascular density: type 4 